\title{
YIELD STABILITY ANALYSIS OF NINE SPRING BREAD WHEAT GENOTYPES IN THE CENTRAL HIGHLANDS OF ETHIOPIA
}

\author{
SOLOMON ASSEFA, BEKELE GELETA and D.G. TANNER' \\ Institute of Agricultural Research (IAR), \\ P.O. Box 2003, Addis Ababa, Ethiopia \\ 'CIMMYT/CIDA East African Cereals Program, \\ P.O. Box 5689, Addis Ababa, Ethiopia
}

(Received 6 October 1994; accepted i8 March 1995)

\begin{abstract}
Eight promising bread wheat lines and one standard check cultivar were evaluated for grain yield performance, stability and adaptation across nine environments of the central highlands of Ethiopia. Results of the combined analysis of variance for grain yield showed highly significant effects of genotypes, environments, and genotype by environment interaction. The mean grain yields for individual lines ranged from 3249 to $4762 \mathrm{~kg} \mathrm{ha}^{-1}$. When the genotypic grain yields were subjected to stability analysis against an environmental index, the regression coefficients for individual lines ranged from 0.406 to 1.451 . Among the lines tested, HAR 1696 and Enkoy were the two most stable genotypes across all environments, while two of the four highest yielding lines, HAR 1349 and HAR 1709, appeared to be specifically adapted to favorable growing conditions. The test line HAR 1685 exhibited superior yield performance across all environments, and was recommended for release in $\mathbf{1 9 9 4}$ for commercial production in Ethiopia.
\end{abstract}

Key Words: Multilocation testing, Triticum aestivum

\section{RÉSUMÉ}

Huit lignées prometeuses de blé à pain et un cultivar de temoin standard étaient évalués pour leur performance en rendement en grains, leur stabilité et leur adaptation à travers neuf environnements des hauts plateaux du centre de l'Éthiopie. Les résultats de l'analyse de variance combinées pour le rendement de grains a montré des effets très significatifs des génotypes, des environnements et de l'interaction entre le génotype et l'environnement. Le rendement moyen de graines pour les lignées individuelles variait de 3249 à $4762 \mathrm{~kg} \mathrm{ha}^{-1}$. Quand les rendements génotypiques de graine étaient sujet d'analyse de stabilité en rapport avec l'indice environnemental, les coéfficients de régression pour les lignés individuelles variaient de 0.406 à 1.451. Parmis les lignées testées, HAR1696 et Enkoy étaient les deux génotypes les plus stables à travers tous les environnements, tandis que deux des quatre lignées au rendements le plus élevé, le HAR 1349 et le HAR 1709, semblaient être spécifiquement adaptées aux conditions de production favorables. La lignée d'évaluation HAR1685 a montré une performance supérieure à travers tous les environnements, et était recommendée pour dissémination en 1994 pour la production commerciale en Éthiopie.

Mots Clés: Essais multilocaux, Triticum aestivum 


\section{INTRODUCTION}

Developing crop cultivars that perform well across a wide range of environmental conditions has long been a major challenge to plant breeders. In practice, genotype by environment interaction complicates the identification of superior genotypes (Allard and Bradshaw, 1964). Although it is important to detect such interactions by conducting yield trials over a series of environments, this alone gives no measure of the stability of individual genotypes. Hence, stability measurements are important since they give an indication of the adaptability of genotypes to general or specific conditions (Getinet, 1988; Hailu, 1988).

Bread wheat (Triticum aestivum L.) is one of the major cereal crops grown in the medium and high altitude zones of the central highlands of Ethiopia. In order to realize sustainable wheat production in this region, there is a need to develop high yielding bread wheat cultivars which exhibit adequate stability of yield performance across a range of diverse growing conditions.

The Ethiopian national bread wheat breeding program relies on multilocational testing to evaluate genotypes in different wheat growing environments (Getinet, 1988; Hailu, 1991, Bekele et al., 1992). Information on the adaptation and stability of genotypes over years and locations is highly desirable and can serve as a basis for the selection of broadly adapted and stable cultivars.

Finlay and Wilkinson (1963) developed an analysis of variance for yield stability using regression coefficients to study the adaptation of barley cultivars. The two important indices in their analysis are the regression coefficient and mean yield across all environments. They interpreted regression coefficients approximating 1.0 as being indicative of average stability and, when associated with high mean yield, genotypes are considered to have acceptable adaptation and stability. Genotypes with $b<1.0$ were considered to be specifically adapted to unfavorable environments, while those with $b>1.0$ were judged as being adapted to relatively favorable environments. Eberhart and Russell (1966) similarly used coefficients of regression to classify the yield stability of genotypes. In addition, the concept of deviation from regression was considered to be an important parameter. They defined a genotype with desirable adaptation and stability as one having a high mean yield, a regression coefficient equal to unity, and a deviation from regression equal to zero $\left(\mathrm{s}_{\mathrm{f}}^{2}=0.0\right)$.

For quantitative traits such as grain yield, the relative contribution of genotype by environment interaction influences the rate of progress in selection. Hence, under Ethiopian conditions where wheat is grown across a diverse range of agro-ecological zones, identifying genotypes with minimal interaction across environments or possessing high grain yield stability (Solomon, 1994) is an important consideration in cultivar release and recommendation.

The objectives of the present study were, therefore, to determine the yield performance and stability of nine spring bread wheat genotypes across a range of environments, and to recommend those which are high yielding and broadly adapted for production in the central highlands of Ethiopia.

\section{MATERIALS AND METHODS}

A yield trial, consisting of one commercially grown spring bread wheat cultivar and eight promising elite lines, was conducted at three different locations in the central highlands of Ethiopia during the 1990,1991, and 1992 cropping seasons. The genotypes and their parentage and pedigrees are listed in Table 1.

Each location in a given year was considered as an individual environment. The locations differed in altitude, soil characteristics and other climatic factors, representing a range of growing conditions (Table 2).

The experiments were carried out using a randomized complete block design with four replications. Plots consisted of six rows $2.5 \mathrm{~m}$ in length and $20 \mathrm{~cm}$ apart $\left(3 \mathrm{~m}^{2}\right)$. The seed rate used was $150 \mathrm{~kg} \mathrm{ha}^{-1}$, and recommended fertilizer doses and cultural practices were used at each location (Getinet, 1988). The center four rows of each plot $\left(2 \mathrm{~m}^{2}\right)$ were harvested for grain yield evaluation.

Analytical procedures used were: 1) an F-test of significance for the grain yield data combined over environments and genotypes (Allard and Bradshaw, 1964; Hailu, 1988); 2) all genotype means for each trial were subjected to a stability 
test against an environmental index following the procedures described by Eberhart and Russell (1966) and Finlay and Wilkinson (1963); 3) the regression coefficients obtained were tested for significance using the Student's t-test; and 4) from the same analysis, deviations from regression and coefficients of determination were calculated.

\section{RESULTS AND DISCUSSION}

The performance of the nine bread wheat genotypes was evaluated over nine environments (location by year combinations) which differed in altitude, soil type, and seasonal climatic factors (Table 2). Environmental mean yields ranged from 2.4 to $4.0 \mathrm{tha}^{-1}$.

TABLE 1. Parentage and pedigrees of nine bread wheat lines tested in the central highlands of Ethiopia in 1990-1992

\begin{tabular}{|c|c|}
\hline Line & Pedigree \\
\hline Enkoy (check) & HEBRAND SeV/(WIS $245 \times$ SUP51) $\times\left[(\text { FR-FN/ } /)^{2} . A\right]$ \\
\hline HAR 1349 & 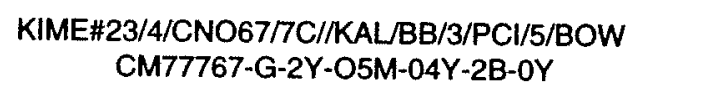 \\
\hline HAR 1331 & $\begin{array}{c}\text { L2266-1406 } 101 \times \text { BUCNPM-MOS } 83.11 .4 .8 \times \text { NAC } \\
\text { CM61550-C-1Y-1M-1Y-1M-1Y-2M-OY }\end{array}$ \\
\hline HAR 1407 & $\begin{array}{l}\text { COOKNEE"S"//DOVE"S"/SERI } \\
\text { CM69279-C-2Y-1M-5Y-1M-OY }\end{array}$ \\
\hline HAR 1522 & $\begin{array}{l}\text { BOW"S"/BUC"S" } \\
\quad \text { CM74005-8M-1Y-03M-5Y-2B-0Y }\end{array}$ \\
\hline HAR 1685 & $\begin{array}{l}\text { ND VG9144//KAL/BB/3/YACO"S"/4/NEE\#5"S" } \\
\text { CM85836-50Y-OM-OY-3M-OY }\end{array}$ \\
\hline HAR 1709 & $\begin{array}{l}\text { BOW28 x Romany BC } \\
\text { ET 1297-HO-3HO-1HO-15HO-OHO }\end{array}$ \\
\hline HAR 1595 & $\begin{array}{l}F_{3} .71 / T R M / / B U C^{n} S^{n} / 3 / L / R A " S^{n} \\
\text { CM79630-F-1M-010Y-04M-5Y-0B }\end{array}$ \\
\hline HAR 1696 & $\begin{array}{c}\text { IAS58/4/KAL/BB//CJ"S"/3/ALD"S"/5/BOW"S" } \\
\text { CM81812-12Y-06PZ-4Y-16M-0Y }\end{array}$ \\
\hline
\end{tabular}

TABLE 2. Altitude, rainfall, soil characteristics and major diseases of bread wheat at the experimental sites during the 1990-1992 crop seasons

\begin{tabular}{|c|c|c|c|c|}
\hline & & Holetta & Ginchi & Debre/Zeit \\
\hline $\begin{array}{l}\text { Altitude (m asl) } \\
\text { Rainfall (mm) }\end{array}$ & & 2400 & 2250 & 1860 \\
\hline Jun.-Sept. & $\begin{array}{l}1990 \\
1991 \\
1992\end{array}$ & $\begin{array}{l}1245 \\
1007 \\
1095\end{array}$ & $\begin{array}{c}1158 \\
875 \\
1069\end{array}$ & $\begin{array}{l}867 \\
572 \\
548\end{array}$ \\
\hline $\begin{array}{l}\text { Soil type } \\
\text { Soil texture } \\
\mathrm{pH}\left(\mathrm{H}_{2} \mathrm{O}\right) \\
\text { Organic matter (\%) } \\
\text { Disease }\end{array}$ & & $\begin{array}{c}\text { Nitosol } \\
\text { Clay loam } \\
4.9 \\
4.7 \\
\text { ST, YR, SR }\end{array}$ & $\begin{array}{l}\text { Vertisol } \\
\text { Clay } \\
6.5 \\
2.3 \\
\text { LR }\end{array}$ & $\begin{array}{l}\text { Vertisol } \\
\text { Clay } \\
6.6 \\
2.0 \\
\text { LR, SR }\end{array}$ \\
\hline
\end{tabular}

1: ST = Septoria tritici blotches; YR = Yellow rust (Puccinia strifformis); LR = Leaf rust (Puccinia recondita); $\mathrm{SR}=$ Stem rust $($ Puccinia graminis f.sp. tritici) . 
The combined analysis of variance for grain yield exhibited a highly significant effect of the genotype and environment components (Table 3 ), indicating significant variation in the genetic yield potential of the tested wheat germplasm, and a significant effect of seasons and locations. However, the location component was more pronounced than the season component, accounting for $70 \%$ of the sum of squares (SS) for environments. The genotype by environment interaction component was also highly significant, suggesting that the performance ranking of genotypes was not constant. Genotype by location interaction accounted for $73 \%$ of the SS for genotype by environment interaction.

The highest yielding line, HAR 1685, had a mean grain yield of $4762 \mathrm{~kg} \mathrm{ha}^{-1}$ while the lowest yielding entry, HAR 1331, had a mean yield of $3249 \mathrm{~kg} \mathrm{ha}^{-1}$. The overall mean yield was 3900 $\mathrm{kg} \mathrm{ha}^{-1}$ (Table 4).

Since the genotype by environment component was highly significant, the individual lines were subjected to stability analysis following the model proposed by Eberhart and Russell (1966). The basic assumption for this analysis is that genotypic performance is positively and linearly related to favorable environmental conditions when other production factors are controlled.

Estimates of three stability parameters are shown in Table 4, and four representative regression lines are illustrated in Fig. 1. The slopes for HAR 1331 and HAR 1595 were significantly lower than 1.0 $(P<0.05)$, and those for HAR 1349, HAR 1685 and HAR 1709 were higher than 1.0

TABLE 3. Combined analysis of variance for grain yield $\left(\mathrm{g} \mathrm{plot}^{-1}\right)$ of nine bread wheat genotypes evaluated across nine environments in the central highlands of Ethiopia, 1990-1992

\begin{tabular}{lcccc}
\hline Source & $\begin{array}{c}\text { Degrees of } \\
\text { freedom }\end{array}$ & $\begin{array}{c}\text { Mean } \\
\text { squares }\end{array}$ & $\begin{array}{c}F \\
\text { test }\end{array}$ & Probability \\
\hline Environments (E) & 8 & 2270826 & 46.48 & $* * *$ \\
Reps(Environments) & 27 & 48854 & & $* * *$ \\
Genotypes (G) & 8 & 278239 & 4.11 & $* * *$ \\
GXE & 64 & 67621 & 6.93 & \\
Error & 216 & 9761 & & $*$ \\
\hline
\end{tabular}

***: Significant at the $0.1 \%$ level of probability. C.V. $=12.7 \%$.

TABLE 4. Mean grain yields and estimates of stability for grain yield of nine bread wheat genotypes grown in nine environments, 1990-1992

\begin{tabular}{lcccc}
\hline Line & $\begin{array}{c}\text { Mean yield } \\
\left(\mathrm{kg} \mathrm{ha}^{-1}\right)\end{array}$ & & \multicolumn{2}{c}{ Stability parameters' $^{\prime}$} \\
\cline { 4 - 5 } & & $\mathrm{b}$ & $\mathrm{s}^{2}{ }_{\mathrm{d}}$ & $\mathbf{r}_{2}$ \\
\hline Enkoy (check) & 3819 & 0.902 & 0.49 & 0.760 \\
HAR 1349 & 4145 & $1.451^{*}$ & 0.87 & 0.868 \\
HAR 1331 & 3249 & 0.406 & $2.21^{\circ}$ & 0.365 \\
HAR 1407 & 4019 & 1.156 & 0.66 & 0.938 \\
HAR 1522 & 3716 & 0.809 & 0.64 & 0.882 \\
HAR 1685 & 4762 & $1.200^{\circ}$ & 0.71 & 0.954 \\
HAR 1709 & 4110 & $1.271^{*}$ & 1.08 & 0.939 \\
HAR 1595 & 3433 & $0.750^{\circ}$ & 0.55 & 0.882 \\
HAR 1696 & 3847 & 0.955 & 0.36 & 0.958 \\
\hline Mean & 3900 & & & \\
LSD(P =0.05) & 612 & & & \\
\hline
\end{tabular}

\footnotetext{
$1: b=$ slope of regression line; $s^{2}{ }_{d}=$ standard deviation from regression; $r=$ coefficient of determination.

$\therefore$ : Indicates b values significantly different from unity or $\mathrm{S}^{2}$ values significantly different from 0 at the 5 and $10 \%$ levels, respectively.
} 
$(P<0.10)$; the coefficients for the remaining four wheat lines were not significantly different from unity. Of the total of nine tested lines, four genotypes (i.e., HAR 1685, HAR 1349, HAR 1709 and HAR 1407) exhibited grain yields above the grand mean and regression coefficients (b) greater than or equal to 1 (Table 4). Thus, these lines appeared to be superior in performance and were responsive to favorable growing conditions. The commercially grown cultivar Enkoy and HAR 1696 , both of which had regression coefficients close to 1 ( $b=0.902$ and 0.955 , respectively), a minimal deviation from regression, and an intermediate grain yield, appeared to be stable across a wide range of growing conditions. The two lowest yielding genotypes, HAR 1595 and HAR 1331, had slopes below unity $(b<1.0)$, exhibiting poor grain yield response to favorable environments. This situation is seen clearly in Table 4 for HAR 1595 which yielded below the mean across all environments. The environmental response of the genotype HAR $1331(b=0.406$ and $s_{d}^{2}=2.21$ ) did not fit the linear regression model as indicated by the significant $s_{d}^{2}$ value.

The values for the coefficients of determination (Table 4) suggested that from 37 to $96 \%$ of the variation in grain yield of individual lines was accounted for by regression on the environmental index. Thus, regression analysis has considerable predictive value in estimating the stability of test lines. Similar results were also obtained by Getinet (1988) and Sariahet al. (1990) with Ethiopian and

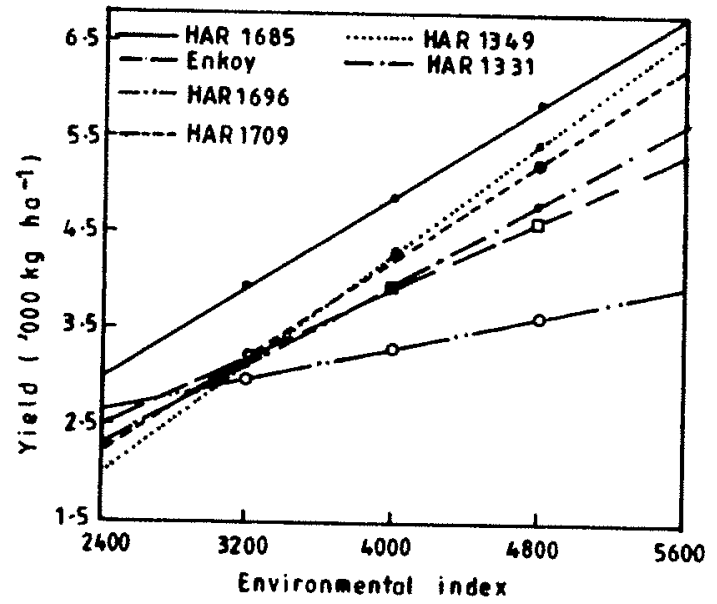

Figure 1.Regression lines of six bread wheat varieties tested in nine environments of the central highlands of Ethiopia
Tanzanian bread wheat genotypes, respectively.

In accordance with the criteria set for stability analysis, as described by Eberhart and Russell (1966) and Finlay and Wilkinson (1963), HAR 1696 and Enkoy were the two most stable genotypes across the diverse growing environments, having regression coefficients close to unity, and a minimal deviation from regression (Table 4). Thus, these two lines exhibited general stability; HAR 1696 can be recommended for production across the diverse growing environments of the central highlands of Ethiopia, assuming that adequate levels of disease resistance are maintained. The cultivar Enkoy, although it appeared stable, cannot be recommended for production in the future due to the breakdown of its resistance to stem rust (Puccinia graminis f.sp. tritici) during the 1993 cropping season.

In environments with favorable growing conditions for bread wheat production, the four highest yielding lines, HAR 1685, HAR 1407, HAR 1349, and HAR 1709, appeared to be highly productive. However, the latter two exhibited a pronounced crossover effect under low yield conditions (see HAR 1709 in Fig. 1); these two lines should probably be restricted to production in high yield potential environments. HAR 1685 exhibited the highest mean yield of all nine genotypes, significantly outyielding the other eight lines, and was ranked first across all the environments included in this study (Fig. 1). In fact, HAR 1685 was recommended for release in 1994 for commercial production across all the major wheat zones of Ethiopia. By contrast, the lines HAR 1595 and HAR 1331 seemed to be poorly adapted to the more favourable environments of the central highlands.

In conclusion, since the evaluated genotypes varied in response to the diverse growing conditions of the central highlands, future recommendations for cultivar release should take into account these findings. Stability analysis of grain yield data collected across locations and years appears to be of value for recommending cultivars for general or specific environments.

\section{ACKNOWLEDGEMENTS}

The authors extend their gratitude to the technical staff of the cooperating stations for assistance in 
executing the project. We also wish to thank Mr. Abuhay Takele for his invaluable advice and constructive comments.

\section{REFERENCES}

Allard, R.W. and Bradshaw, A.D. 1964. Implications of genotype-environment interactions. Crop Science 4: 503-507.

Bekele Geleta, Hailu Gebre-Mariam, Tesfaye Tessema, Getinet Gebeyehu and van Ginkel. M. 1992. Stability of yield and harvest index of improved bread wheat varieties in Ethiopia. In: Seventh Regional Wheat Workshop for Eastern, Central and Southern Africa. Tanner, D.G. and Mwangi, W. (Eds.), pp. 56-63. CIMMYT, Mexico, D.F.

Eberhart, S.A. and Russell, W.A. 1966. Stability parameters for comparing varieties. Crop Science 6: 36-40.

Finlay, K.W. and Wilkinson, G.N. 1963. The analysis of adaptation in a plant breeding program. Australian Journal of Agricultural Research 14: 742-754.

Getinet Gebeyehu. 1988. Grain yield stability of bread wheat cultivars in the highlands of Ethiopia. In: Fifth Regional Wheat Workshop for Eastern, Central and Southern Africa and the Indian Ocean. van Ginkel, M. and Tanner, D.G..(Eds.), pp. 61-65. CIMMYT, Mexico, D.F.

Hailu Gebre-Mariam. 1988. Yield stability analysis in bread wheat. In: Bulletin of the First Annual Conference of the Crop Science Committee of Ethiopia 1: 6-8. CSCE. Addis Ababa, Ethiopia.

Hailu Gebre-Mariam. 1991. Bread wheat breeding and genetic research in Ethiopia. In: Wheat Research in Ethiopia: A Historical Perspective. Hailu Gebre-Mariam, Tanner, D.G. and Mengistu Hulluka (Eds.), pp. 73-93. IAR/CIMMYT, Addis Ababa, Ethiopia.

Sariah, M.A., Ndondi, R.V. and Mollel, M.J. 1990. Grain yield potential and adaptation of ten bread wheat varieties in Tanzania. In: Sixth Regional Wheat Workshop for Eastern, Central and Southem Africa. van Ginkel, M., Tanner, D.G. and Mwangi, W. (Eds.), pp. 224-228. CIMMYT, Mexico. D.F.

Solomon Assefa. 1994. Recommended bread wheat technologies in the central highlands of Ethiopia. In: Institute of Agricultural Research Newsletter 2: 7-9. IAR, Addis Ababa, Ethiopia. 